\title{
The crystal structural of the $\mathrm{Er}_{10} \mathrm{Ga}_{3} \mathrm{Si}_{3}$ ternary compounds
}

\section{Changsheng Qin ${ }^{1, a}$, Lei Hu ${ }^{1, b}$, Chao Zeng ${ }^{2}$, Bing He ${ }^{1}$, Ming Qin ${ }^{1, c}$}

${ }^{1}$ Department of physics and communication engineering, Baise University, Baise, Guangxi 533000, PR China

${ }^{2}$ Guangxi International Business Vocational College, Nanning, Guangxi, 530005, China

aqcs501@126.com, bdreamhulei@163.com, cqmkj01@126.com

Keywords: Crystal structure; X-ray diffraction; Rietveld methods

\begin{abstract}
A ternary compound $\mathrm{Er}_{10} \mathrm{Ga}_{3} \mathrm{Si}_{3}$ was synthesized and studied by means of X-ray powder diffraction technique using Rietveld methods. The ternary compound $\mathrm{Er}_{10} \mathrm{Ga}_{3} \mathrm{Si}_{3}$ crystallizes in the hexagonal structure, space group $P 6_{3} / \mathrm{mcm}\left(\mathrm{N}_{0} .193\right)$ with the $\mathrm{Mn}_{5} \mathrm{Si}_{3}$ structure type and lattice parameters $\mathrm{a}=8.3595(1) \AA, \mathrm{n}=6.3095(1) \AA, \mathrm{V}=381.84 \AA^{3}, \mathrm{z}=1$ and $\rho_{\mathrm{x}}=8.55 \mathrm{~g} / \mathrm{cm}^{3}$.
\end{abstract}

\section{Introduction}

Searching for novel compounds, especially rare earth compounds, with excellent properties is very important for developing new potential function materials. Compounds with the $\mathrm{Mn}_{5} \mathrm{Si}_{3}$-type structure have been sources of useful chemical instruction as well as of significant experimental errors, both deriving from a remarkable flexibility of this particular structure type to accommodate a great range of host substitutions as well as to bind diverse interstitials [1-2]. In the R-Ga-Si ternary system, the crystal structures of $\mathrm{REGa}_{\mathrm{x}} \mathrm{Si}_{2-\mathrm{x}-\mathrm{y}}(\mathrm{RE}=\mathrm{Ho}, \mathrm{Er}, \mathrm{Tm} ; 0.33 \leq \mathrm{x} \leq 0.40,0.10 \leq \mathrm{y} \leq 0.18$ ) [3], EuGaSi [4], $\mathrm{Ga}_{1.34} \mathrm{NdSi}_{0.66}$ and $\mathrm{NdGa}_{0.86} \mathrm{Si}_{1.14}$ [5] have been reported. To the best of our knowledge, ternary intermetallic compound $\mathrm{Er}_{10} \mathrm{Ga}_{3} \mathrm{Si}_{3}$ have not been reported in literature. This work reports on the crystal structure of $\mathrm{Er}_{10} \mathrm{Ga}_{3} \mathrm{Si}_{3}$.

\section{Experimental details}

The sample of $\mathrm{Er}_{10} \mathrm{Ga}_{3} \mathrm{Si}_{3}$ with a total mass of $2 \mathrm{~g}$ was prepared by arc melting using a nonconsumable tungsten electrode and a water-cooled copper tray under argon atmosphere. Erbium (purity of 99.9\%), gallium (purity of 99.9\%), and silicon (purity of 99.999\%) were used as the starting materials. Titanium was used as an oxygen getter during the melting process. The sample was remelted three times in order to ensure the complete fusion and homogeneity. The weight loss during melting was less than $1 \%$. Following the melting, the ingot was wrapped in a tantalum foil, sealed under vacuum in a silica tube and annealed at $1123 \mathrm{~K}$ for 4 weeks, then cooled down at a rate of $10 \mathrm{~K} / \mathrm{h}$ to room temperature. The sample was ground in an agate mortars and pestled to particle sizes of no larger than $45 \mu \mathrm{m}$. High-quality powder X-ray diffraction patterns of the sample were collected at room temperature using a Rigaku Smart Lab 2006 powder diffractometer equipped with a $\mathrm{Cu} \mathrm{K \alpha}$ radiation $(40 \mathrm{kV}, 150 \mathrm{~mA})$ and a graphite monochromator. The scan range was from $10.00^{\circ}$ to $100.00^{\circ}(2 \theta)$ with a step size of $0.02^{\circ}$ and a count time of 1 s per step.

\section{Results and discussion}

The powder X-ray diffraction pattern of $\mathrm{Er}_{10} \mathrm{Ga}_{3} \mathrm{Si}_{3}$ was successfully indexed using the Jade 5.0 [6] program in a hexagonal unit cell with the lattice parameters a=8.3595(1) $\hat{A}, c=6.3095(1) \AA \hat{\text {. }}$ Reflection conditions ( $\bar{h} h 0 l: l=2 n, 000 l: l=2 n$ ) pointed to 3 space groups $P 6_{3} / \mathrm{mcm}$ (No. 193), $\bar{p} 6 c 2$ (No. 188) and $P 6_{3} \mathrm{~cm}$ (No. 185) [7]. By comparing crystallographic characteristics of the $\mathrm{Er}_{10} \mathrm{Ga}_{3} \mathrm{Si}_{3}$ compound with those presented in the structure type database, it was found that $\mathrm{Er}_{10} \mathrm{Ga}_{3} \mathrm{Si}_{3}$ and $\mathrm{Mn}_{5} \mathrm{Si}_{3}$ [8] have the same structure type (space group $P 6_{3} / \mathrm{mcm}$ ). So the space group $P 6_{3} / \mathrm{mcm}$ (No.193) and the atomic position parameters of $\mathrm{Mn}_{5} \mathrm{Si}_{3}$ were taken as the starting 
values to refine the structural parameters of $\mathrm{Er}_{10} \mathrm{Ga}_{3} \mathrm{Si}_{3}$. Structure refinement of $\mathrm{Er}_{10} \mathrm{Ga}_{3} \mathrm{Si}_{3}$ was then performed using the DBWS9807 program [9]. The Er sites corresponded to the Mn sites, and both $\mathrm{Ga}$ and Si occupied the Si site in $\mathrm{Mn}_{5} \mathrm{Si}_{3}$. When the 6 (g) site occupied by $50 \% \mathrm{Ga}$ and $50 \% \mathrm{Si}$, the goodness-of-fit parameters of these refinements led to the best values: $R_{p}=8.97 \%, R_{w p}=12.03 \%$, $\mathrm{R}_{\mathrm{B}}=6.42 \%, \mathrm{R}_{\mathrm{F}}=4.27 \%$. The details of the Rietveld refinement of $\mathrm{Er}_{10} \mathrm{Ga}_{3} \mathrm{Si}_{3}$ are summarized in Table 1, and the atomic positions and thermal displacement factors are presented in Table 2. The observed, calculated, and residuals X-ray powder diffraction patterns of $\mathrm{Er}_{10} \mathrm{Ga}_{3} \mathrm{Si}_{3}$ are shown in Figure. 1. A set of interatomic distances in $\mathrm{Er}_{10} \mathrm{Ga}_{3} \mathrm{Si}_{3}$ are given in Table 3. The crystal structure of the $\mathrm{Er}_{10} \mathrm{Ga}_{3} \mathrm{Si}_{3}$ compound is shown in Figure 2.

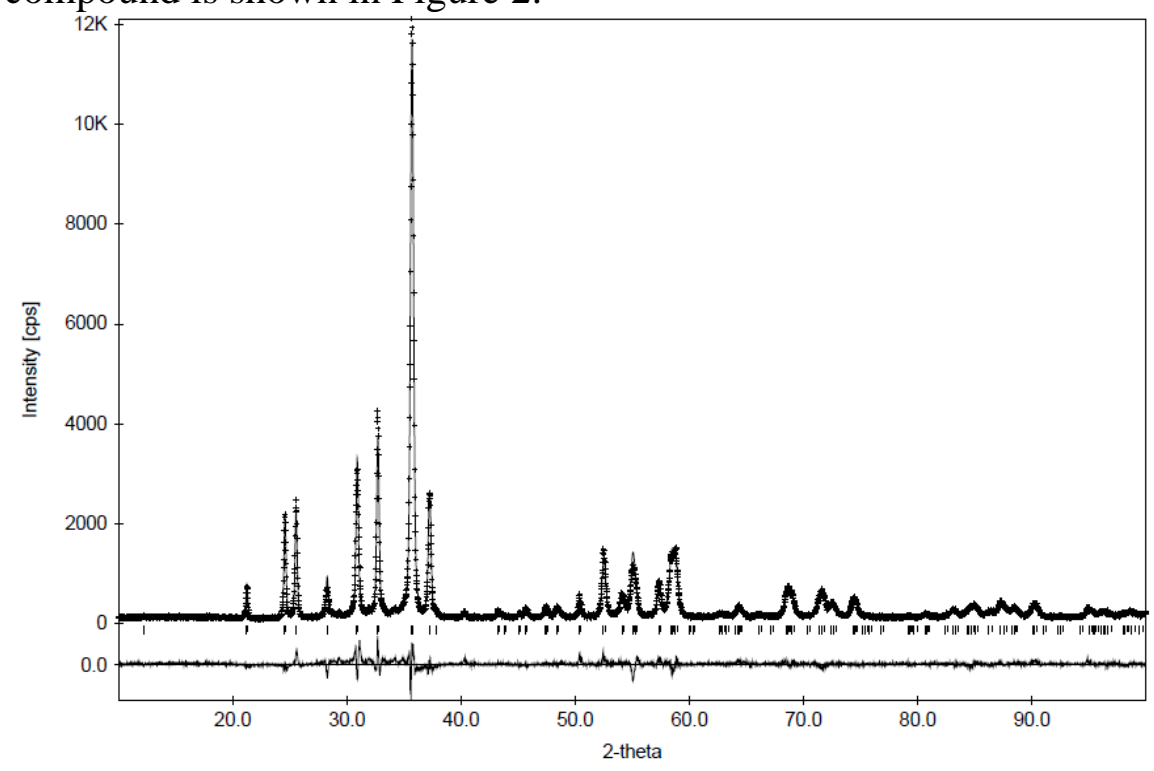

Fig.1. Observed, calculated and residuals X-ray powder diffraction patterns of $\mathrm{Er}_{10} \mathrm{Ga}_{3} \mathrm{Si}_{3}$

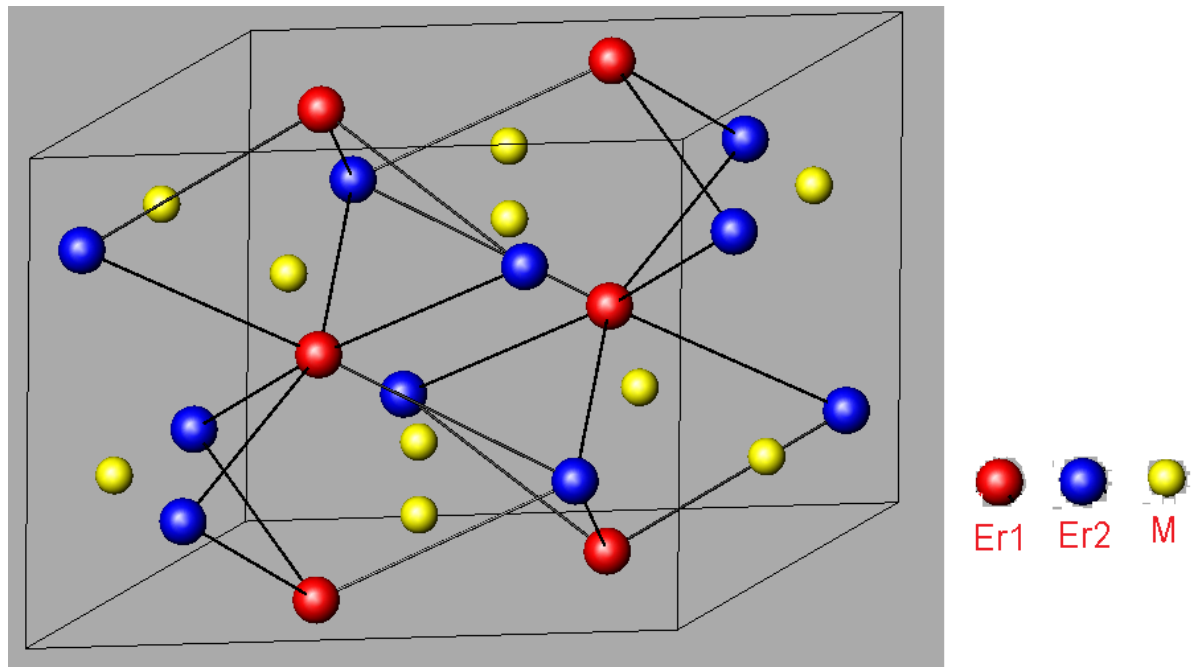

Fig.2. Crystal structure of the $\mathrm{Er}_{10} \mathrm{Ga}_{3} \mathrm{Si}_{3}$ compound (M=50\% $\mathrm{Ga}+50 \% \mathrm{Si}$ ) 
Table 1. Rietveld refinement data of $\mathrm{Er}_{10} \mathrm{Ga}_{3} \mathrm{Si}_{3}$

\begin{tabular}{|c|c|}
\hline Formula & $\mathrm{Er}_{10} \mathrm{Ga}_{3} \mathrm{Si}_{3}$ \\
\hline Space group & $P 6_{3} / m c m$ (No.193) \\
\hline Radiation wavelength $\mathrm{Cu} K \alpha_{1}(\AA)$ & 1.54056 \\
\hline Unit cell parameters $(\AA)$ & $\mathrm{a}=8.3595(1), \mathrm{c}=6.3095(1)$ \\
\hline Unit-cell volume $\left(\AA^{3}\right)$ & 381.84 \\
\hline Calculated density $\left(\mathrm{g} / \mathrm{cm}^{3}\right)$ & 8.55 \\
\hline Formula units per unit cell & $Z=1$ \\
\hline Scan range & $10^{\circ} \leq 2 \theta \leq 100^{\circ}$ \\
\hline \multicolumn{2}{|l|}{ Residual values } \\
\hline$R_{\mathrm{p}}$ & 0.0897 \\
\hline$R_{\mathrm{wp}}$ & 0.1203 \\
\hline$R_{\mathrm{B}}$ & 0.0642 \\
\hline$R_{\mathrm{F}}$ & 0.0427 \\
\hline
\end{tabular}

$$
\begin{array}{ll}
R_{P}=\frac{\sum\left|Y_{i}(o b s)-Y_{i}(c a l c)\right|}{\sum Y_{i}(o b s)} \quad R_{W P}=\left\{\frac{\sum \omega_{i}\left[Y_{i}(o b s)-Y_{i}(c a l c)\right]^{2}}{\sum \omega_{i}\left[Y_{i}(o b s)\right]^{2}}\right\}^{1 / 2} \\
R_{B}=\frac{\sum\left|I_{H}(o b s)-I_{H}(c a l c)\right|}{\sum I_{H}(o b s)} \quad R_{F}=\frac{\sum\left|\left[I_{H}(o b s)\right]^{1 / 2}-\left[I_{H}(c a l c)\right]^{1 / 2}\right|}{\sum\left(I_{H}(o b s)\right)^{1 / 2}}
\end{array}
$$

Table 2 Atomic coordinates and thermal parameters for $\mathrm{Er}_{10} \mathrm{Ga}_{3} \mathrm{Si}_{3}$

\begin{tabular}{lllllll}
\hline Atom & position & $\mathrm{X}$ & $\mathrm{Y}$ & $\mathrm{Z}$ & Occ. & $\mathrm{B}\left(\AA^{2}\right)$ \\
\hline Er1 & $4 \mathrm{~d}$ & $1 / 3$ & $2 / 3$ & 0 & 1 & $0.76(7)$ \\
Er2 & $6 \mathrm{~g}$ & $0.2400(2)$ & 0 & 0.25 & 1 & $0.47(5)$ \\
$\mathrm{Ga}$ & $6 \mathrm{~g}$ & $0.6020(5)$ & 0 & 0.25 & $0.50(1)$ & $0.59(10)$ \\
$\mathrm{Si}$ & $6 \mathrm{~g}$ & $0.6020(5)$ & 0 & 0.25 & $0.50(1)$ & $0.59(10)$ \\
\hline
\end{tabular}


Table 3 Selected interatomic distances $(\AA)$ for $\operatorname{Er}_{10} \mathrm{Ga}_{3} \mathrm{Si}_{3}$

\begin{tabular}{|c|c|c|c|c|c|c|c|}
\hline \multicolumn{2}{|c|}{ Atom-atom } & Distance $(\AA)$ & multiplicity & \multicolumn{2}{|c|}{ Atom-atom } & \multirow{2}{*}{$\begin{array}{c}\text { distance }(\AA) \\
2.902(5)\end{array}$} & \multirow{2}{*}{$\begin{array}{c}\text { multiplicity } \\
\times 2\end{array}$} \\
\hline $\mathrm{M}$ & -Er1 & $3.006(1)$ & $\times 4$ & $\mathrm{Er}_{2}$ & $-\mathrm{M}$ & & \\
\hline & -Er2 & $2.902(5)$ & $\times 2$ & & $-M$ & $3.026(2)$ & $\times 1$ \\
\hline & $-\mathrm{M}$ & $3.596(1)$ & $\times 3$ & & $-\mathrm{Er}_{1}$ & $3.611(5)$ & $\times 4$ \\
\hline & $-\mathrm{Er}_{2}$ & $3.026(2)$ & $\times 1$ & & -Er2 & $3.475(3)$ & $\times 2$ \\
\hline \multirow[t]{3}{*}{$\mathrm{Er}_{1}$} & -Er1 & $3.155(2)$ & $\times 2$ & & & & \\
\hline & -Er2 & $3.611(5)$ & $\times 6$ & & & & \\
\hline & $-\mathrm{M}$ & $3.006(1)$ & $\times 3$ & & & & \\
\hline
\end{tabular}

\section{Acknowledgements}

This work was supported by the Scientific Foundation of Guangxi High Education(Grant No. KY2015LX385).

\section{References}

[1] J.D. Corbett, E. Garcia, A.M. Guloy, W.-M.Hurng, Y.-U. Kwon, E.A. Leon-Escamilla, Chem. Mater., 10 (1998), p. 2824-2836.

[2] P.A. Maggard and J.D. Corbett, Inorg. Chem. 40 (2001), p.1352-1357.

[3] G.M. Darone, B. Hmiel, J. Zhang, S. Saha, K. Kirshenbaum, R. Greene, J. Paglione, S. Bobev, Journal of Solid State Chemistry. 201 (2013), p.191-203.

[4] You Tae-Soo, Yu. Grin', G.J. Miller, Inorganic Chemistry. 46 (2007), p.8801-8811.

[5] Ya.O.Tokaychuk, A.O. Fedorchuk, O.I. Bodak, I.R.Mokra, Journal of Alloys Compd.367 (2004), p.64-69.

[6] Jade5, XRD Pattern Processing, Materials Data, Inc., 1999.

[7] International Tables for Crystallography Volume A: Space-Group Symmetry Editor Theo Hahn, Fifth Edition 2002, Published by Springer, P.O. Box 17, 3300 AA Dordrecht, The Netherlands.

[8] J. Leciejewicz, B. Penc, A. Szytula, A. Jezierski, A. Zygmunt, Acta Physica Polonica, A. 113 (2008), p.1193-1203

[9] R.A. Young, A.C. Larson, C.O. Paive-Santos, User's Guide to Program DBWS9807 for Rietveld Analysis of X-ray and Neutron Powder Diffraction Patterns with a PC and Various Other Computers, School of Physics, Georgia Institute of Technology, Atlanta, GA, 2000. 